\title{
Raster charting products in an ENC-first era
}

\author{
Christie Ence $^{\mathrm{a}, *}$, Shachak Pe’eri ${ }^{\mathrm{a}}$, John Nyberg ${ }^{\mathrm{a}}$ \\ ${ }^{a}$ Office of Coast Survey, National Oceanic and Atmospheric Administration, Silver Spring, MD, USA (Christie.Ence@NOAA.gov, \\ Shachak.peeri@NOAA.gov and John.Nyberg@NOAA.gov) \\ * Corresponding author: Shachak Pe’eri (Shachak.peeri@NOAA.gov)
}

Keywords: Nautical chart, re-scheme, Electronic Navigation Chart, raster charts

\begin{abstract}
:
Nautical charts are an essential tool for marine navigation. Despite the introduction of global positioning systems (GPS) and electronic navigational tools that present navigation data in a vector format on a display, paper charts are still the preferred choice for many mariners. Interestingly, since the introduction of Electronic Navigation Charts (ENCs) more than thirty years ago, the size of commercial vessels has increased more than four-fold, modern navigational systems have become more sophisticated, and recreational boaters have joined professional mariners in using electronic chart displays. Marine and coastal users of all types are expecting higher resolution and more precision in location of the charted features, and shorter update times for data sources to be published on the chart. With NOAA's new plan to "standardized, consistent gridded framework" that is optimized for digital displays, it leaves the future of paper charts in question. In order to support a raster-based maintenance system, it is now possible to translate encoding attributes of vector objects into standardized chart symbols and labels. Thus, simplifying workflow processes for paper and raster chart production. This paper discusses NOAA Marine Chart Division's raster workflow in an ENC-first production line. The paper reviews the benefits of the new desktop tools and web-services for providing chart updates in a timely manner for a broader community.
\end{abstract}

